\title{
The effect of zinc to aluminium molar ratio on the formation of zinc-aluminium-4- chlorophenoxyacetate nanocomposite
}

\begin{abstract}
Layered organic-inorganic hybrid nanocomposite material containing 4-chlorophenoxy acetate, (4CPA) intercalated into zinc-aluminium-layered double hydroxide (ZAL) was prepared by direct self-assembly method for the formation of Zn-Al-4CPA nanocomposite (ZAC). Various $\mathrm{Zn} 2+$ to $\mathrm{Al} 3+$ molar ratios, $\mathrm{R}$ ranging from 1 to 6 were used in the preparation of the mother liquor with fixed concentration of 4CPA at $0.4 \mathrm{M}$. The $\mathrm{pH}$ of the solution was adjusted to 7.5 by slow addition of $2 \mathrm{M} \mathrm{NaOH}$. Well-ordered nanolayered organic-inorganic hybrid nanocomposites with the expansion of basal spacing from $8.9 \AA$ in the layered double hydroxide to $19.11021 .2 \AA$ in the resulting nanocomposites were obtained. The FTIR spectra for the nanocomposites showed that the spectrum composed of spectral features of ZAL and 4CPA showing the successful intercalation of the organic moiety into the LDH interlayer. The BET surface area decreased as the XAl value increased while the percentage loading of 4CPA in the nanocomposites increased in the range of $38.9 \mathrm{i} 44.7 \%$ (w/w) as the XAl increased. This shows that the mole ratio of $\mathrm{Zn} 2+$ to $\mathrm{Al} 3+, \mathrm{R}$ in the mother liquor controlled the physicochemical properties of the resulting nanocomposite, $\mathrm{Zn}$-Al4CPA.
\end{abstract}

Keyword: 4-chlorophenoxy acetate; Layered double hydroxide; Nanocomposite; Organicinorganic hybrid 